\title{
Farsightedness and Cautiousness in Coalition Formation*
}

\author{
Ana Mauleon \\ LABORES (URA 362, CNRS), \\ Vincent Vannetelbosch ${ }^{\dagger}$ \\ Université catholique de Lille, \\ France. \\ FNRS, IRES and CORE, \\ Université catholique de Louvain, \\ Belgium.
}

February 13, 2003

\begin{abstract}
We adopt the largest consistent set defined by Chwe [J. of Econ. Theory 63 (1994), 299-235] to predict which coalition structures are possibly stable when players are farsighted. We also introduce a refinement, the largest cautious consistent set, based on the assumption that players are cautious. For games with positive spillovers, many coalition structures may belong to the largest consistent set. The grand coalition, which is the efficient coalition structure, always belongs to the largest consistent set and is the unique one to belong to the largest cautious consistent set.
\end{abstract}

Keywords: coalition formation, farsightedness, cautiousness, positive spillovers, largest consistent set.

JEL Classification: C70, C71, C72, C78.

\footnotetext{
${ }^{*}$ We wish to thank an anonymous referee for valuable comments. Vincent Vannetelbosch is Chercheur Qualifié at the Fonds National de la Recherche Scientifique, Belgium. The research of Ana Mauleon has been made possible by a fellowship of the Fonds Européen de Développement Economique Régional (FEDER). Financial support from the research project TMR Network FMRX CT 960055 Cooperation and Information and from the Belgian French Community's program Action de Recherches Concertée 99/04-235 is gratefully acknowledged.

${ }^{\dagger}$ Corresponding author address : Department of Economics, Université catholique de Louvain, Place Montesquieu 3, B-1348 Louvain-la-Neuve, Belgium. E-mail: vannetelbosch@ires.ucl.ac.be
} 


\section{Introduction}

Many social, economic and political activities are conducted by groups or coalitions of individuals. For example, consumption takes place within households or families; production is carried out by firms which are large coalitions of owners of different factors of production; workers are organized in trade unions or professional associations; public goods are produced within a complex coalition structure of federal, state, and local jurisdictions; political life is conducted through political parties and interest groups; and individuals belong to networks of formal and informal social clubs.

The formation of coalitions has been a major topic in game theory, and has been studied mainly using the framework of cooperative games in coalitional form (see Aumann and Drèze, 1974). Unfortunately, externalities among coalitions cannot be considered within such framework (see Bloch, 1997). As a consequence, the formation of coalitions has been described in the recent years as noncooperative simultaneous or sequential games, which are usually solved using the Nash equilibrium concept or one of its refinements. The most disturbing feature of simultaneous coalition formation games is that the agents cannot be farsighted in the sense that individual deviations cannot be countered by subsequent deviations (see Hart and Kurz, 1983). In order to remedy this weakness sequential coalition formation games have been proposed (see Bloch 1995 and 1996). Nevertheless, these sequential games are quite sensitive to the exact coalition formation process and rely on the commitment assumption. Once some agents have agreed to form a coalition they are committed to remain in that coalition. They can neither leave the coalition nor propose to change the coalition at subsequent stages.

Coalition formation games in effectiveness form as in Chwe (1994) specify what each coalition can do if and when it forms. This representation of games allows us to study economic and social activities where the rules of the game are rather amorphous or the procedures are rarely pinned down (e.g. in sequential bargaining or coalition formation without a rigid protocol), and for which classical game theory could lead to a solution which relies heavily on an arbitrarily chosen procedure or rule. For games in effectiveness form where coalitions can form through binding or non-binding agreements and actions are public, Chwe (1994) has proposed an interesting solution concept, the largest consistent set. This solution concept predicts which coalitions structures are possibly stable and could emerge. Chwe's approach has a number of nice features. Firstly, it does not rely on a very detailed description of the coalition formation process as noncooperative sequential games do. No commitment assumption is imposed. Secondly, it incorporates the farsightedness of the coalitions. A coalition considers the possibility that, once it acts, another coalition might react, a third coalition might in turn react, and so on without limit. 
The largest consistent set suffers from a number of drawbacks, some of them pointed out by Chwe himself. For instance, the largest consistent set may fail to satisfy the requirement of individual rationality. An individual that is given the choice between two moves, where one yields with certainty a higher payoff than the other, might choose the move leading to the lower payoff according to the largest consistent set. This is perhaps somewhat less disturbing than it seems at first sight, since the largest consistent set aims to be a weak concept, a concept that rules out with confidence, but is not so good at picking out. The largest consistent set may also include coalition structures from which some coalition could deviate without the risk of ending worst off in subsequent deviations. Precisely, a coalition structure may be stable because a deviation from it is deterred by a likely subsequent deviation where the initial deviators are equal off. But it might be that any other likely subsequent deviations would not make the initial deviators worst off and at least one of them would make the initial deviators better off. Then, a coalition of cautious players, who give positive weight to all likely subsequent deviations, will deviate for sure from the original coalition structure. In this paper, we introduce cautiousness into the definition of the largest consistent set, which leads to a refinement called the largest cautious consistent set.

Two different notions of a coalitional deviation or move can be found in the gametheoretic literature. Strict deviation: a group of players or a coalition can deviate only if each of its members can be made better off. Weak deviation: a group of players or a coalition can deviate only if at least one of its members is better off while all other members are at least as well off. A weak deviation or move requires only one player to be better off as long as all other members of the group are not worse off, whereas under a strict deviation or move, all deviating players must be better off. We shall distinguish between the indirect strict dominance relation and the indirect weak dominance relation in the definition of the largest (cautious) consistent set. The indirect strict (weak) dominance relation captures the fact that farsighted coalitions consider the end coalition structure that their move(s) may lead to, and that only strict (weak) deviations or moves will be engaged.

We find that the largest (cautious) consistent set is sensitive to the exact definition of the indirect dominance relation. In general there is no relationship between the largest (cautious) consistent set based on the indirect strict dominance and the largest (cautious) consistent set based on the indirect weak dominance. The largest consistent set is never empty whenever the set of coalition structures is finite. Unfortunately, the largest cautious consistent set might be empty in some situations.

However, we show that the largest cautious consistent set refines considerably the 
largest consistent set in coalition formation games satisfying the properties of positive spillovers, negative association, individual free-riding incentives and efficiency of the grand coalition. Positive spillovers restrict the analysis to games where the formation of a coalition by other players increases the payoff of a player. Negative association imposes that, in any coalition structure, small coalitions have greater per-member payoffs than big coalitions. Individual free-riding incentives assume that a player becomes better off leaving any coalition to be alone. An economic situation satisfying these properties is a cartel formation game under Cournot competition. Public goods coalitions satisfy these properties under some conditions.

Many coalition structures may belong to the largest consistent set in coalition formation games satisfying the four properties imposed on the payoffs. The grand coalition always belongs to the largest consistent set. The stand-alone coalition structure (where all players are singletons) is never stable under the largest consistent set based on the indirect weak dominance relation. However, the largest cautious consistent set singles out the grand coalition, which is the efficient coalition structure.

The paper has been organized as follows. In Section 2 we introduce some notations, primitives and definitions of indirect dominance. We present the solution concepts of Chwe (1994), and we propose a refinement, the largest cautious consistent set. In Section 3 we use the above mentioned concepts to predict which coalition structures are stable in coalition formation games with positive spillovers. In Section 4 we analyze and characterize the stable outcomes in the cartel formation game. We also introduce a congestion or monitoring cost and we discuss the role of monitoring costs in the determination of largest consistent sets. Finally, Section 5 concludes.

\section{Farsighted Coalitional Stability}

The players are forming coalitions and inside each coalition formed the members share the coalition gains from cooperation. Let $\mathbb{P}$ be the finite set of coalition structures. A coalition structure $P=\left\{S_{1}, S_{2}, \ldots, S_{m}\right\}$ is a partition of the player set $N=\{1,2, \ldots, n\}, S_{i} \cap S_{j}=\emptyset$ for $i \neq j$ and $\bigcup_{i=1}^{m} S_{i}=N$. Let $\left|S_{i}\right|$ be the cardinality of coalition $S_{i}$. Gains from cooperation are described by a valuation $V$ which maps the set of coalition structures $\mathbb{P}$ into vectors of payoffs in $\mathbb{R}^{n}$. The component $V_{i}(P)$ denotes the payoff obtained by player $i$ if the coalition structure $P$ is formed.

How does the coalition formation proceed? What coalitions can do if and when they form is specified by $\left\{\rightarrow_{S}\right\}_{S \subset N, S \neq \emptyset}$, where $\left\{\rightarrow_{S}\right\}, S \subseteq N$, is an effectiveness relation on $\mathbb{P}$. For any $P, P^{\prime} \in \mathbb{P}, P \rightarrow_{S} P^{\prime}$ means that if the coalition structure $P$ is the status-quo, coalition $S$ can make the coalition structure $P^{\prime}$ the new status-quo. After $S$ deviates 
to $P^{\prime}$ from $P$, coalition $S^{\prime}$ might move to $P^{\prime \prime}$ where $P^{\prime} \rightarrow_{S^{\prime}} P^{\prime \prime}$, etc. All actions are public. If a status-quo $P$ is reached and no coalition decides to move from $P$, then $P$ is a stable coalition structure. A coalition formation game in effectiveness form $G$ is $\left(N, \mathbb{P}, V,\left\{\rightarrow_{S}\right\}_{S \subseteq N, S \neq \emptyset}\right)$.

\subsection{Indirect Strict or Weak Dominance}

As Konishi et al. (1999) mention, the game-theoretic literature uses two different notions of a coalitional deviation or move.

- Strict Deviation: A group of players or a coalition can deviate only if each of its members can be made better off; and

- Weak Deviation: A group of players or a coalition can deviate only if at least one of its members is better off while all other members are at least as well off.

A weak deviation or move requires only one player to be better off as long as all other members of the group are not worse off, whereas under a strict deviation or move, all deviating players must be better off. Hence, we shall distinguish between the indirect strict dominance relation and the indirect weak dominance relation.

The indirect strict dominance relation captures the fact that farsighted coalitions consider the end coalition structure that their move(s) may lead to, and that only strict deviations or moves will be engaged. A coalition structure $P^{\prime}$ indirectly strictly dominates $P$ if $P^{\prime}$ can replace $P$ in a sequence of moves, such that at each move all deviators are better off at the end coalition structure $P^{\prime}$ compared to the status-quo they face. Formally, indirect strict dominance is defined as follows.

Definition 1 A coalition structure $P$ is indirectly strictly dominated by $P^{\prime}$, or $P \ll P^{\prime}$, if there exists a sequence $P^{0}, P^{1}, \ldots, P^{m}$ (where $P^{0}=P$ and $\left.P^{m}=P^{\prime}\right)$ and a sequence $S_{0}, S_{1}, \ldots, S_{m-1}$ such that $P^{j} \rightarrow S_{j} P^{j+1}, V_{i}\left(P^{\prime}\right)>V_{i}\left(P^{j}\right)$ for all $i \in S_{j}$, for $j=0,1, . ., m-$ 1.

Direct strict dominance is obtained by setting $m=1$ in Definition 1. A coalition structure $P$ is directly strictly dominated by $P^{\prime}$, or $P<P^{\prime}$, if there exists a coalition $S$ such that $P \rightarrow_{S} P^{\prime}$ and $V_{i}\left(P^{\prime}\right)>V_{i}(P)$ for all $i \in S$. Obviously, if $P<P^{\prime}$, then $P \ll P^{\prime}$. The definition of the indirect strict dominance relation $\ll$ is traditional: it is customary to require that a coalition will deviate or move only if all of its members are made better off at the end coalition structure, since changing the status-quo is costly, and players have to be compensated for doing so. 
But sometimes some players may be indifferent between the status-quo they face and a possible end coalition structure, while others are better off at this end coalition structure. Then, it should not be too difficult for the players who are better off at this end coalition structure to convince the indifferent players to join them to move towards this end coalition structure. ${ }^{1}$ The indirect weak dominance relation captures this idea. A coalition structure $P^{\prime}$ indirectly weakly dominates $P$ if $P^{\prime}$ can replace $P$ in a sequence of moves, such that at each move all deviators are at least as well off at the end coalition structure $P^{\prime}$ compared to the status-quo they face, and at least one deviator is better off at $P^{\prime}$. Formally, indirect weak dominance is defined as follows.

Definition $2 A$ coalition structure $P$ is indirectly weakly dominated by $P^{\prime}$, or $P \ll P^{\prime}$, if there exists a sequence $P^{0}, P^{1}, \ldots, P^{m}$ (where $P^{0}=P$ and $\left.P^{m}=P^{\prime}\right)$ and a sequence $S_{0}, S_{1}, \ldots, S_{m-1}$ such that $P^{j} \rightarrow_{S_{j}} P^{j+1}, V_{i}\left(P^{\prime}\right) \geq V_{i}\left(P^{j}\right)$ for all $i \in S_{j}$, and $V_{i}\left(P^{\prime}\right)>$ $V_{i}\left(P^{j}\right)$ for some $i \in S_{j}$, for $j=0,1, . ., m-1$.

Direct weak dominance is obtained by setting $m=1$ in Definition 2. A coalition structure $P$ is directly weakly dominated by $P^{\prime}$, or $P \leq P^{\prime}$, if there exists a coalition $S$ such that $P \rightarrow_{S} P^{\prime}, V_{i}\left(P^{\prime}\right) \geq V_{i}(P)$ for all $i \in S$ and $V_{i}\left(P^{\prime}\right)>V_{i}(P)$ for some $i \in S$. Obviously, if $P \leq P^{\prime}$ then $P \ll P^{\prime}$. Also, if $P$ is indirectly strictly dominated by $P^{\prime}$, then $P$ is indirectly weakly dominated by $P^{\prime}$. Of course the reverse is not true. To summarize, we have

$$
\begin{aligned}
& P<P^{\prime} \Rightarrow P \leq P^{\prime} \Rightarrow P \ll P^{\prime} \\
& P<P^{\prime} \Rightarrow P \ll P^{\prime} \Rightarrow P \ll P^{\prime}
\end{aligned}
$$

\subsection{The Largest Consistent Set}

Based on the indirect strict dominance relation, the largest consistent set $L C S(G, \ll)$ due to Chwe (1994) is defined in an iterative way. Chwe (1994) has shown that there uniquely exists a largest consistent set.

Definition 3 Let $Y^{\mathbf{0}} \equiv \mathbb{P}$. Then, $Y^{k}(k=1,2, \ldots)$ is inductively defined as follows: $P \in Y^{k-1}$ belongs to $Y^{k}$ if and only if $\forall P^{\prime}, S$ such that $P \rightarrow_{S} P^{\prime}, \exists P^{\prime \prime} \in Y^{k-1}$, where $P^{\prime}=P^{\prime \prime}$ or $P^{\prime} \ll P^{\prime \prime}$, such that we do not have $V_{i}(P)<V_{i}\left(P^{\prime \prime}\right)$ for all $i \in S$. The largest consistent set $\operatorname{LCS}(G, \ll)$ is $\bigcap_{k>1} Y^{k}$.

That is, a coalition structure $P \in Y^{k-1}$ is stable (at step $k$ ) and belongs to $Y^{k}$, if all possible deviations are deterred. Consider a deviation from $P$ to $P^{\prime}$ by coalition $S$. There

\footnotetext{
${ }^{1}$ For instance, the weak dominance relation makes sense when very small transfers among the deviating group of players are allowed.
} 
might be further deviations which end up at $P^{\prime \prime}$, where $P^{\prime} \ll P^{\prime \prime}$. There might not be any further deviations, in which case the end coalition structure $P^{\prime \prime}=P^{\prime}$. In any case, the end coalition structure $P^{\prime \prime}$ should itself be stable (at step $k-1$ ), and so, should belong to $Y^{k-1}$. If some member of coalition $S$ is worse off or equal off at $P^{\prime \prime}$ compared to the original coalition structure $P$, then the deviation is deterred. Since $\mathbb{P}$ is finite, there exists $m \in \mathbb{N}$ such that $Y^{k}=Y^{k+1}$ for all $k \geq m$, and $Y^{m}$ is the largest consistent set $\operatorname{LCS}(G, \ll)$. If a coalition structure is not in the largest consistent set, it cannot be stable. The largest consistent set is the set of all coalition structures which can possibly be stable.

We define in a similar way the largest consistent set $\operatorname{LCS}(G, \ll)$ based on the indirect weak dominance relation. The proof of Chwe (1994) can be easily adapted to show that there uniquely exists a largest consistent set $\operatorname{LCS}(G, \ll)$.

Definition 4 Let $Y^{0} \equiv \mathbb{P}$. Then, $Y^{k}(k=1,2, \ldots)$ is inductively defined as follows: $P \in Y^{k-1}$ belongs to $Y^{k}$ if and only if $\forall P^{\prime}, S$ such that $P \rightarrow_{S} P^{\prime}, \exists P^{\prime \prime} \in Y^{k-1}$, where $P^{\prime}=P^{\prime \prime}$ or $P^{\prime} \ll P^{\prime \prime}$, such that we do not have $V_{i}(P) \leq V_{i}\left(P^{\prime \prime}\right)$ for all $i \in S$ and $V_{i}(P)<V_{i}\left(P^{\prime \prime}\right)$ for some $i \in S$. The largest consistent set $\operatorname{LCS}(G, \ll)$ is $\bigcap_{k \geq 1} Y^{k}$.

That is, a coalition structure $P \in Y^{k-1}$ is stable (at step $k$ ) and belongs to $Y^{k}$, if all possible deviations are deterred. Consider a deviation from $P$ to $P^{\prime}$ by coalition $S$. There might be further deviations which end up at $P^{\prime \prime}$, where $P^{\prime} \ll P^{\prime \prime}$. There might not be any further deviations, in which case the end coalition structure $P^{\prime \prime}=P^{\prime}$. In any case, the end coalition structure $P^{\prime \prime}$ should itself be stable (at step $k-1$ ), and so, should belong to $Y^{k-1}$. If some member of coalition $S$ is worse off or all members of $S$ are equal off at $P^{\prime \prime}$ compared to the original coalition structure $P$, then the deviation is deterred. Since $\mathbb{P}$ is finite, there exists $m \in \mathbb{N}$ such that $Y^{k}=Y^{k+1}$ for all $k \geq m$, and $Y^{m}$ is the largest consistent set $\operatorname{LCS}(G, \ll)$.

The following example shows that the largest consistent set is sensitive to the exact definition of the indirect dominance relation. Figure 1 depicts a three-player coalition formation game in effectiveness form, where only three coalition structures are feasible: $\{12,3\},\{1,2,3\}$ and $\{1,23\}$. The payoff vectors associated with those three partitions are given in Figure 1 as well as the possible moves from each partition. For instance, player 1 can move from $\{12,3\}$ where he gets 1 to $\{1,2,3\}$ where he gets 2 . We have $\{12,3\}<$ $\{1,2,3\}$ (hence $\{12,3\} \leq\{1,2,3\})$ and $\{1,2,3\} \leq\{1,23\}$. It follows that $\operatorname{LCS}(G, \ll)=$ $\{\{1,2,3\},\{1,23\}\}$ and $\operatorname{LCS}(G, \ll)=\{\{12,3\},\{1,23\}\}$. In general, these two indirect dominance relations (weak or strict) might yield two very different largest consistent sets. 


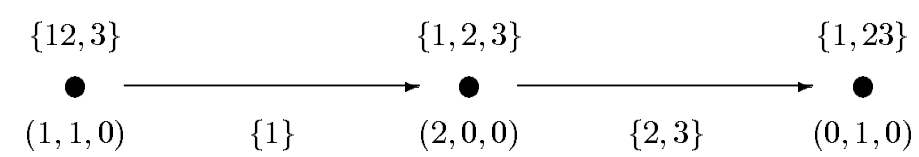

FiguRE 1. The largest consistent set is sensitive to the indirect dominance relation.

\subsection{The Largest Cautious Consistent Set}

Similarly to the rationalizability concepts, ${ }^{2}$ the largest consistent set does not determine what will happen but what can possibly happen. The following example shows that the largest consistent set is not consistent with cautiousness. Figure 2 depicts a three-player coalition formation game in effectiveness form, where the feasible coalition structures are: $\{123\},\{1,23\},\{13,2\}$ and $\{1,2,3\}$. The payoff vectors associated with those partitions are given in Figure 2 as well as the possible moves from each partition. For instance, player 1 can move from $\{123\}$ where he gets 1 to $\{1,23\}$ where he gets 2 . We have $\{123\}<\{1,23\},\{1,23\}<\{1,2,3\},\{1,23\}<\{13,2\}$ and $\{123\} \ll\{13,2\}$. It follows that $\operatorname{LCS}(G, \ll)=\operatorname{LCS}(G, \ll)=\{\{123\},\{1,2,3\},\{13,2\}\}$. The coalition structure $\{123\}$ belongs to the largest consistent because the deviation to $\{1,23\}$ is deterred by the subsequent deviation to $\{1,2,3\}$ where the original deviator is equal off. But player 1 cannot end worse off by engaging a move from $\{123\}$ compared to what he gets in $\{123\}$. So, if player 1 is cautious he would engage the move from $\{123\}$ to $\{1,23\}$.

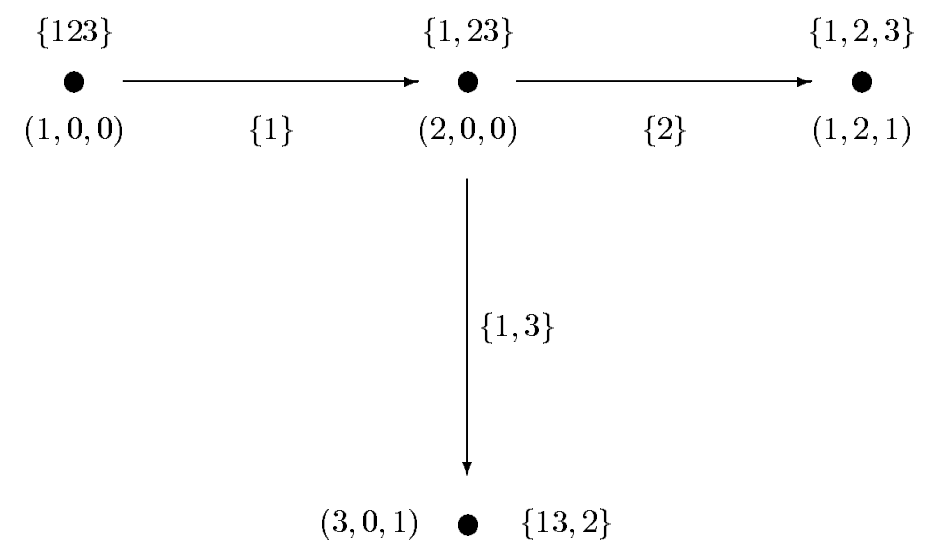

FigURE 2. The largest consistent set is not consistent with cautiousness.

We propose to refine the largest consistent set by applying the spirit of some refinements of the rationalizability concept to the largest consistent set. It leads to the definition of the largest cautious consistent set derived from either the indirect strict dominance relation

\footnotetext{
${ }^{2}$ See Bernheim (1984), Herings and Vannetelbosch (1999), Pearce (1984).
} 
or the indirect weak dominance relation. Formally, the largest cautious consistent set $\operatorname{LCCS}(G, \ll)$ based on the indirect strict dominance is defined in an iterative way.

Definition 5 Let $Z^{0} \equiv \mathbb{P}$. Then, $Z^{k}(k=1,2, \ldots)$ is inductively defined as follows: $P \in Z^{k-1}$ belongs to $Z^{k}$ if and only if $\forall P^{\prime}, S$ such that $P \rightarrow_{S} P^{\prime}, \exists \alpha=\left(\alpha\left(P^{1}\right), \ldots, \alpha\left(P^{m}\right)\right)$ satisfying $\sum_{j=1}^{m} \alpha\left(P^{j}\right)=1, \alpha\left(P^{j}\right) \in(0,1)$, that gives only positive weight to each $P^{j} \in$ $Z^{k-1}$, where $P^{\prime}=P^{j}$ or $P^{\prime} \ll P^{j}$, such that we do not have

$$
V_{i}(P)<\sum_{\substack{P^{j} \in Z^{k-1} \\ P^{\prime}=P^{j} \text { or } P^{\prime} \ll P^{j}}} \alpha\left(P^{j}\right) \cdot V_{i}\left(P^{j}\right) \text { for all } i \in S .
$$

The largest cautious consistent set $\operatorname{LCCS}(G, \ll)$ is $\bigcap_{k \geq 1} Z^{k}$.

The idea behind the largest cautious consistent set $\operatorname{LCCS}(G, \ll)$ is that once a coalition $S$ deviates from $P$ to $P^{\prime}$, this coalition $S$ should contemplate the possibility to end with positive probability at any coalition structure $P^{\prime \prime}$ not ruled out ${ }^{3}$ and such that $P^{\prime}=P^{\prime \prime}$ or $P^{\prime} \ll P^{\prime \prime}$. Hence, a coalition structure $P$ is never stable if a coalition $S$ can engage a deviation from $P$ to $P^{\prime}$ and by doing so there is no risk that some coalition members will end worse off or equal off.

The definition, based on the indirect weak dominance, of the largest cautious consistent set $\operatorname{LCCS}(G, \ll)$ is as follows.

Definition 6 Let $Z^{0} \equiv \mathbb{P}$. Then, $Z^{k}(k=1,2, \ldots)$ is inductively defined as follows: $P \in Z^{k-1}$ belongs to $Z^{k}$ if and only if $\forall P^{\prime}, S$ such that $P \rightarrow_{S} P^{\prime}, \exists \alpha=\left(\alpha\left(P^{1}\right), \ldots, \alpha\left(P^{m}\right)\right)$ satisfying $\sum_{j=1}^{m} \alpha\left(P^{j}\right)=1, \alpha\left(P^{j}\right) \in(0,1)$, that gives only positive weight to each $P^{j} \in$ $Z^{k-1}$, where $P^{\prime}=P^{j}$ or $P^{\prime} \ll P^{j}$, such that we do not have

$$
\begin{aligned}
& V_{i}(P) \leq \sum_{\substack{P^{j} \in Z^{k-1} \\
P^{\prime}=P^{j} \text { or } P^{\prime} \ll P^{j}}} \alpha\left(P^{j}\right) \cdot V_{i}\left(P^{j}\right) \text { for all } i \in S \text {, and } \\
& V_{i}(P)<\sum_{\substack{P^{j} \in Z^{k-1} \\
P^{\prime}=P^{j} \text { or } P^{\prime}} P^{j}} \alpha\left(P^{j}\right) \cdot V_{i}\left(P^{j}\right) \text { for some } i \in S .
\end{aligned}
$$

The largest cautious consistent set $\operatorname{LCCS}(G, \ll)$ is $\bigcap_{k \geq 1} Z^{k}$.

Once a coalition $S$ deviates from $P$ to $P^{\prime}$, this coalition $S$ should contemplate the possibility to end with positive probability at any coalition structure $P^{\prime \prime}$ not ruled out

\footnotetext{
${ }^{3}$ On the contrary, in the largest consistent set once a coalition $S$ deviates from $P$ to $P^{\prime}$, this coalition $S$ only contemplates the possibility to end with probability one at a coalition structure $P^{\prime \prime}$ not ruled out and such that $P^{\prime}=P^{\prime \prime}$ or $P^{\prime} \ll P^{\prime \prime}$.
} 
and such that $P^{\prime}=P^{\prime \prime}$ or $P^{\prime} \ll P^{\prime \prime}$. Hence, a coalition structure $P$ is never stable if a coalition $S$ can engage a deviation from $P$ to $P^{\prime}$ and doing so some coalition members will be better off but there is no risk that some coalition members will end worse off.

Obviously, the largest cautious consistent set is a refinement of the largest consistent set.

Theorem $1 \operatorname{LCCS}(G, \ll) \subseteq \operatorname{LCS}(G, \ll)$ and $\operatorname{LCCS}(G, \ll) \subseteq \operatorname{LCS}(G, \ll)$.

Proof. It suffices to show that $Z^{k} \subseteq Y^{k}$ for all $k$. We prove this by induction on $k$. For $k=0$, this is true since $Z^{0}=Y^{0}$. Now, let $Z^{k-1} \subseteq Y^{k-1}$ and let $P \in Z^{k}$. Then it is straightforward that $P \in Y^{k}$.

In the example of Figure 2 we get as expected $\operatorname{LCCS}(G, \ll)=\operatorname{LCCS}(G, \ll)=$ $\{\{1,2,3\},\{13,2\}\}$. Unfortunately, the largest cautious consistent set LCCS $(G, \ll)$ or $\operatorname{LCCS}(G, \ll)$ might be empty in some situations. In general there is no relationship between $\operatorname{LCCS}(G, \ll)$ and $\operatorname{LCCS}(G, \ll)$. In the example of Figure 1 , we have $\operatorname{LCCS}(G, \ll)$ $=\{\{1,2,3\},\{1,23\}\}$ and $\operatorname{LCCS}(G, \ll)=\{\{12,3\},\{1,23\}\}$. Nevertheless, we will show that the largest cautious consistent set refines considerably the largest consistent set in coalition formation games with positive spillovers (and that, both sets $\operatorname{LCCS}(G, \ll)$ and $\operatorname{LCCS}(G, \ll)$ coincide).

The following example (see Figure 3 ) illustrates that the largest cautious consistent set $\operatorname{LCCS}(G, \ll)$ or $\operatorname{LCCS}(G, \ll)$ might be empty, while the largest consistent set $\operatorname{LCS}(G, \ll)$ or $\operatorname{LCS}(G, \ll)$ is not. Figure 3 depicts a three-player coalition formation game in effectiveness form. The payoff vectors associated with the partitions are given in Figure 3 as well as the possible moves from each partition. For instance, the coalition of players 2 and 3 can move from $\{13,2\}$ where they get respectively 1 to $\{1,23\}$ where they get 0 . We have $\{123\}<\{12,3\},\{1,2,3\}<\{13,2\},\{1,23\}<\{12,3\}$, $\{123\} \ll\{13,2\}$, but also $\{12,3\} \ll\{13,2\}$ and $\{13,2\} \ll\{12,3\}$. It follows that $\operatorname{LCCS}(G, \ll)=\operatorname{LCCS}(G, \ll)=\emptyset$ but $\operatorname{LCS}(G, \ll)=\operatorname{LCS}(G, \ll)=\{\{12,3\},\{13,2\}\}$. Indeed, it is intuitively reasonable that no outcome can be possibly cautiously stable in this example. Player 1 or the coalition formed by players 2 and 3 cannot end worse off by engaging a move from $\{12,3\}$ and $\{13,2\}$, respectively.

One condition on the game $G$ in effectiveness form which guarantees that the largest cautious consistent set is nonempty is that the coalition formation game in effectiveness form is acyclic.

Definition 7 A coalition formation game in effectiveness form $G$ is acyclic if the effectiveness relation, $\left\{\rightarrow_{S}\right\}_{S \subseteq N}$, is such that there does not exist a sequence $P^{0}, P^{1}, \ldots, P^{m}$ 


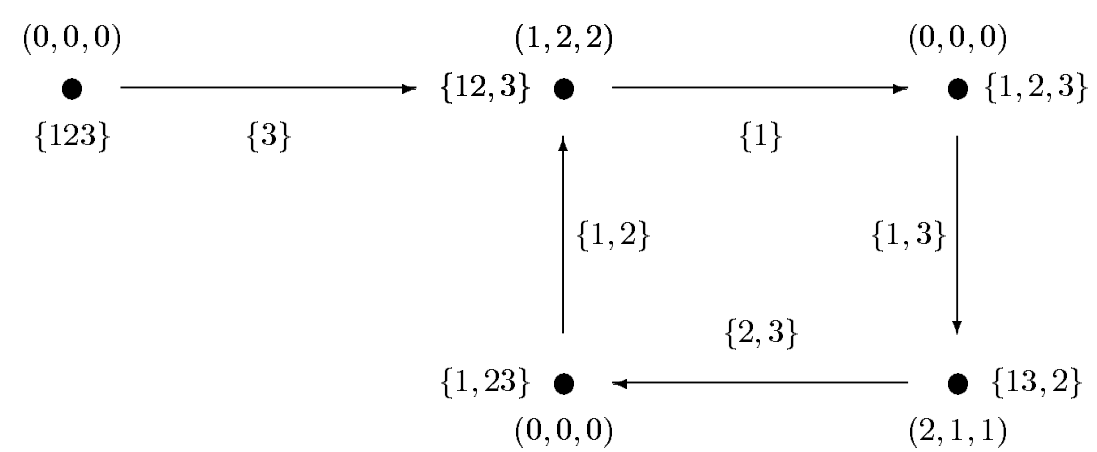

FIGURE 3. The largest cautious consistent set might be empty.

(where $P^{0}=P$ and $P^{m}=P$ ) and a sequence $S_{0}, S_{1}, \ldots, S_{m-1}$ such that $P^{j} \rightarrow_{S_{j}} P^{j+1}$, for $j=0,1, . ., m-1$.

Theorem 2 If the coalition formation game in effectiveness form $G$ is acyclic, then the sets $\operatorname{LCCS}(G, \ll)$ and $\operatorname{LCCS}(G, \ll)$ are nonempty.

Proof. Since $\mathbb{P}$ is finite and $G$ is acyclic, there exists $P \in \mathbb{P}$ such that there does not exist $P^{\prime} \in \mathbb{P}$ and $S \subseteq N$ such that $P \rightarrow_{S} P^{\prime}$. In other words $P$ is an end coalition structure from which no move is possible. Hence, $P$ belongs to $\operatorname{LCCS}(G, \ll)$ and $\operatorname{LCCS}(G, \ll)$.

The acyclic property is a sufficient but not necessary condition that guarantees the nonemptiness of the largest cautious consistent set. Indeed, the coalition formation games with positive spillovers analyzed next are cyclic games for which the largest cautious consistent set is nonempty.

\section{Coalition Formation with Positive Spillovers}

\subsection{Conditions on the Payoffs}

Gains are assumed to be positive, $V_{i}(P)>0$ for all $i \in N$, for all $P \in \mathbb{P}$. We consider $|N|>2$. We assume symmetric or identical players and equal sharing of the coalition gains among coalition members. ${ }^{4}$ That is, in any coalition $S_{i}$ belonging to $P, V_{j}(P)=V_{l}(P)$ for all $j, l \in S_{i}, i=1, \ldots, m$. So, let $V\left(S_{i}, P\right)$ denote the payoff obtained by any player belonging to $S_{i}$ in the coalition structure $P$. We focus on coalition formation games satisfying the following conditions on the per-member payoffs.

\footnotetext{
${ }^{4}$ Ray and Vohra (1999) have provided a justification for the assumption of equal sharing rule. In an infinite-horizon model of coalition formation among symmetric players with endogenous bargaining, they have shown that in any equilibrium without delay there is equal sharing. See also Bloch (1996).
} 
(P.1) Positive Spillovers. $V\left(S_{i}, P \backslash\left\{S_{1}, S_{2}\right\} \cup\left\{S_{1} \cup S_{2}\right\}\right)>V\left(S_{i}, P\right)$ for all players belonging to $S_{i}, S_{i} \neq S_{1}, S_{2}$.

Condition (P.1) restricts our analysis to games with positive spillovers, where the formation of a coalition by other players increases the payoff of a player.

(P.2) Negative Association. $V\left(S_{i}, P\right)<V\left(S_{j}, P\right)$ if and only if $\left|S_{i}\right|>\left|S_{j}\right|$.

Condition (P.2) imposes that, in any coalition structure, small coalitions have higher per-member payoffs than big coalitions.

(P.3) Individual Free-Riding. $V\left(\{j\}, P \backslash\left\{S_{i}\right\} \cup\left\{S_{i} \backslash\{j\},\{j\}\right\}\right)>V\left(S_{i}, P\right)$ for all $j \in S_{i}$, $S_{i} \in P$.

Condition (P.3) is related to the existence of individual free-riding incentives. That is, if a player leaves any coalition to be alone, then he is better off.

(P.4) Efficiency. $\nexists P=\left\{S_{1}, S_{2}, \ldots, S_{m}\right\} \in \mathbb{P}$ such that $P \neq\{N\}$ and $\sum_{i=1}^{m} V\left(S_{i}, P\right) \cdot$ $\left|S_{i}\right| \geq V(N) \cdot|N|$.

Finally, condition (P.4) assumes that the grand coalition is the only efficient coalition structure with respect to payoffs, where $V(N)$ denotes the payoff of any player belonging to the grand coalition $\{N\}$.

An economic situation satisfying these four conditions is a cartel formation game with Cournot competition as in Bloch (1997) and Yi (1997). Let $p(q)=a-q$ be the inverse demand ( $q$ is the industry output). The industry consists of $|N|$ identical firms. Inside each cartel, we assume equal sharing of the benefits obtained from the cartel's production. Once stable agreements on cartel formation have been reached, we observe a Cournot competition among the cartels. The payoff for each firm in each possible coalition structure is well defined. Firm $i$ 's cost function is given by $d \cdot q_{i}$, where $q_{i}$ is firm $i$ 's output and $d$ $(a>d)$ is the common constant marginal cost. As a result, the per-member payoff in a cartel of size $|S|$ is, for all firms belonging to $S$,

$$
V(S, P)=\frac{(a-d)^{2}}{|S| \cdot(|P|+1)^{2}},
$$

where $|P|$ is the number of cartels within $P$.

Lemma 1 Output cartels in a Cournot oligopoly with the inverse demand function $p(q)=$ $a-q$ and the cost function $d\left(q_{i}\right)=d \cdot q_{i}$ satisfy $(P .1)-(P .4)$. 
Yi (1997) asserted that conditions (P.1) and (P.2) are satisfied. It is straightforward to show that (P.3) and (P.4) are also satisfied.

A second economic application of games with positive spillovers are economies with pure public goods. The model we study is inspired from Bloch (1997), Yi (1997) and Ray and Vohra (2001) wherein we introduce congestion. The economy consists of $|N|$ agents. At cost $d_{i}\left(q_{i}\right)$, agent $i$ can provide $q_{i}$ units of the public good. Let $q=\sum_{i} q_{i}$ be the total amount of public good. The utility each agent obtains from the public good depends positively on the total amount of public good provided, but negatively on the number of coalition partners: $U_{i}(q)=(|S|)^{-\alpha} \cdot q$ for all $i \in S$, where parameter $\alpha>0$ measures the degree of congestion. Each agent owns a technology to produce the public good, and the cost of producing the amount $q_{i}$ of the public good is given by $d_{i}\left(q_{i}\right)=\frac{1}{2}\left(q_{i}\right)^{2}$. Since individual cost functions are convex and exhibit decreasing returns to scale, it is cheaper to produce an amount $q$ of public goods using all technologies than using a single technology. In stage one the coalition formation takes place. Inside each coalition, we assume equal sharing of the production. Once a coalition structure has been formed, each coalition of agents acts noncooperatively. On the contrary, inside every coalition, agents act cooperatively and the level of public good is chosen to maximize the sum of utilities of the coalition members. That is, for any coalition structure $P=\left\{S_{1}, S_{2}, \ldots, S_{m}\right\}$, the level of public good $q_{S_{i}}$ chosen by the coalition $S_{i}$ solves

$$
\max _{q_{S_{i}}}\left|S_{i}\right| \cdot\left[\left(\left|S_{i}\right|\right)^{-\alpha}\left(q_{S_{i}}+\sum_{j \neq i} q_{S_{j}}\right)-\frac{1}{2}\left(\frac{q_{S_{i}}}{\left|S_{i}\right|}\right)^{2}\right]
$$

yielding a total level of public good provision for the coalition $S_{i}$ equal to $q_{S_{i}}=\left(\left|S_{i}\right|\right)^{2-\alpha}$, $i=1, \ldots, m$. The per-member payoff in a coalition of size $\left|S_{i}\right|$ is given by

$$
V\left(S_{i}, P\right)=\left(\left|S_{i}\right|\right)^{-\alpha} \cdot \sum_{j=1}^{m}\left(\left|S_{j}\right|\right)^{2-\alpha}-\frac{1}{2}\left(\left|S_{i}\right|\right)^{2-2 \alpha},
$$

for all agents belonging to $S_{i}, i=1, \ldots, m$.

Contrary to the cartel formation game with Cournot competition, it depends on the number of agents $|N|$ and the degree of congestion $\alpha$ whether public goods coalitions satisfy conditions (P1)-(P4). For instance, public goods coalitions with utility function $U_{i}(q)=(|S|)^{-.15} \cdot q$ for all $i \in S$ and cost function $d_{i}\left(q_{i}\right)=\frac{1}{2}\left(q_{i}\right)^{2}$ satisfy (P.1)-(P.4) if $|N| \in[4,6]$. Notice that, for $|N|<4$ the condition (P.3) is violated, while for $|N|>6$ it is (P.4) which is violated. 


\subsection{The Effectiveness Relation}

Remember that what coalitions can do if and when they form is specified by $\left\{\rightarrow_{S}\right\}_{S \subseteq N, S \neq \emptyset}$, where $\left\{\rightarrow_{S}\right\}, S \subseteq N$, is an effectiveness relation on $\mathbb{P}$. Restrictions are imposed on the coalition formation process through the effectiveness relation $\left\{\rightarrow_{S}\right\}$ in $G ; P \rightarrow_{S} P^{\prime}$ if and only if (i) $\left\{S_{i} \backslash\left(S_{i} \cap S\right): S_{i} \in P\right\}=\left\{S_{i}^{\prime} \in P^{\prime}: S_{i}^{\prime} \subseteq N \backslash S\right\}$ and (ii) $\exists\left\{S_{1}^{\prime}, \ldots, S_{l}^{\prime}\right\} \subseteq P^{\prime}$ such that $\bigcup_{j=1}^{l} S_{j}^{\prime}=S$. Condition (i) simply means that no simultaneous deviations are possible. If the players in $S$ deviate leaving their coalition(s) in $P$, the non-deviating players do not move. Nevertheless, once $S$ has moved, the players not in $S$ can react to the deviation of $S$. Condition (ii) simply allows the deviating players in $S$ to form one or several coalitions in the new status-quo $P^{\prime}$. Non-deviating players do not belong to those new coalitions.

\subsection{Stable Coalition Structures}

Before stating the results, we introduce some definitions or notations. A coalition structure $P$ is symmetric if and only if $\left|S_{i}\right|=\left|S_{j}\right|$ for all $S_{i}, S_{j} \in P$. We denote by $P^{*}=\{N\}$ the grand coalition and by $\bar{P}$ the stand-alone coalition structure: $\bar{P}=\left\{S_{1}, \ldots, S_{n}\right\}$ with $\left|S_{i}\right|=1$ for all $S_{i} \in \bar{P}$ ( $P^{*}$ and $\bar{P}$ are symmetric coalition structures).

The following two lemmas partially characterize the largest consistent set for the coalition formation game in effectiveness form $G$ under conditions (P.1)-(P.4). Lemma 2 states that any coalition structure, wherein some coalition members would receive less than in the stand-alone coalition structure, is never stable.

Lemma 2 Under (P.1)-(P.4), if there exists $S \in P$ such that $V(S, P)<V\left(S^{\prime}, \bar{P}\right)$, then $P \notin \operatorname{LCS}(G, \ll)$ and $P \notin L C S(G, \ll)$.

Proof. Condition (P.2) implies that in any coalition structure $P, V\left(S_{i}, P\right)<V\left(S_{j}, P\right)$ if and only if $\left|S_{i}\right|>\left|S_{j}\right|$. To prove Lemma 2 , we proceed by steps.

Step one. Firstly, we show that all coalition structures $P \in \mathbb{P}$ containing only one coalition $S$ with $|S|>1$ and $V(S, P)<V\left(S^{\prime}, \bar{P}\right)$, do not belong to $L C S(G, \ll)$ and $\operatorname{LCS}(G, \ll)$. Obviously, $P<\bar{P}$ and the deviation $P \rightarrow_{S} \bar{P}$ cannot be deterred. Indeed, any deviation from $\bar{P}$ of players that did not belong to $S$ in $P$ will improve, by (P.1), the payoff of players that were in $S$ (in $P$ ) and are singletons in $\bar{P}$. Therefore, $P \notin L C S(G, \ll)$ and $P \notin \operatorname{LCS}(G, \ll)$.

Step two. Secondly, we show that all coalition structures $P \in \mathbb{P}$ containing only two coalitions $S_{1}, S_{2}$ with $\left|S_{1}\right| \geq\left|S_{2}\right|>1$ and $V\left(S_{1}, P\right)<V\left(S^{\prime}, \bar{P}\right)$, do not belong to $\operatorname{LCS}(G, \ll)$ and $\operatorname{LCS}(G, \ll)$. Condition (P.1) implies that the coalition $S_{1}$ has incentives 
to split into singletons. Indeed, $V\left(\{j\}, P^{\prime}\right)>V\left(S^{\prime}, \bar{P}\right) \forall j \in S_{1}$ and $P<P^{\prime}$ where $P^{\prime}=P \backslash S_{1} \cup\{j\}_{j \in S_{1}}$. The deviation $P \rightarrow_{S_{1}} P^{\prime}$ cannot be deterred. Indeed,

- if $V\left(S_{2}, P^{\prime}\right)<V\left(S^{\prime}, \bar{P}\right)$, then using the argumentation of step one, the deviation $P^{\prime} \rightarrow_{S_{2}} \bar{P}$ is not deterred and $\bar{P} \gg P$. Therefore, $P \notin \operatorname{LCS}(G, \ll)$ and $P \notin \operatorname{LCS}(G, \ll)$.

- if $V\left(S_{2}, P^{\prime}\right)>V\left(S^{\prime}, \bar{P}\right)$, we have to show that any deviation from $P^{\prime}$ of players in $N \backslash S_{1}$ will never make players in $S_{1}$ worse off than in $P$. Two kinds of deviations are possible. First, the players in $S_{2}$ form a bigger coalition with players not in $S_{1}$. Then, by condition (P.1), the players in $S_{1}$ that now are singletons obtain a payoff even greater than in $P^{\prime}$. Second, some player(s) leave(s) $S_{2}$ to form singleton(s). Then, the players that were in $S_{1}$ are worse than in $P^{\prime}$ but, by (P.1), they are better off or at least not worse off than in $\bar{P}$, and $V\left(S_{1}, P\right)<V\left(S^{\prime}, \bar{P}\right)$. Therefore, there is no other coalition structure $P^{\prime \prime}$ such that $P^{\prime \prime} \gg P^{\prime}$ and $V\left(\{j\}, P^{\prime \prime}\right)<V\left(S_{1}, P\right)$ for some $j \in S_{1}$. Hence, $P \notin L C S(G, \ll)$ and $P \notin \operatorname{LCS}(G, \lll)$.

Step three. Thirdly, proceeding as above, we can show that all coalition structures $P \in \mathbb{P}$ containing only three coalitions $S_{1}, S_{2}, S_{3}$ with $\left|S_{1}\right| \geq\left|S_{2}\right| \geq\left|S_{3}\right|>1$ and $V\left(S_{1}, P\right)<V\left(S^{\prime}, \bar{P}\right)$, do not belong to $\operatorname{LCS}(G, \ll)$ and $\operatorname{LCS}(G, \ll)$. And so on.

The grand coalition structure which is the efficient one always belongs to the largest consistent set, and is possibly stable.

Lemma $3 \operatorname{Under}(P .1)-(P .4), P^{*} \in \operatorname{LCS}(G, \ll)$ and $P^{*} \in \operatorname{LCS}(G, \ll)$.

Proof. To prove that $P^{*} \in Y^{k}(k \geq 1)$ we have to show that for all $P \neq P^{*}$ we have $P$ $\ll P^{*}$. That is, we show that $P^{*}$ could be stable since any deviation $P^{*} \rightarrow_{S} P$ can be deterred by the threat of ending in $P^{*}$. The proof is done in two steps.

Step A. By (P.2) and (P.4) the players belonging to the biggest coalition (in size) in any $P \neq P^{*}$ are worse than in $P^{*}$. Also, all players prefer $P^{*}$ to $\bar{P}$, and $P^{*}>\bar{P}$.

Step $B$. Take the sequence of moves where at each move one player belonging to the biggest coalition (in the current coalition structure) deviates to form a singleton, until the coalition structure $\bar{P}$ is reached. From $\bar{P}$ occurs the deviation $\bar{P} \rightarrow_{N} P^{*}$.

Therefore, $(A)-(B)$ imply that $P^{*} \gg P$ for all $P \neq P^{*}$.

From these two lemmas, we obtain a sufficient condition such that the largest consistent set singles out the grand coalition.

Proposition 1 Under (P.1)-(P.4), if each non-symmetric coalition structure $P \in \mathbb{P}$ is such that there exists $S \in P$ satisfying $V(S, P)<V\left(S^{\prime}, \bar{P}\right)$, then $\operatorname{LCS}(G, \ll)=\left\{P^{*}\right\}$ and $\operatorname{LCS}(G, \ll)=\left\{P^{*}\right\}$. 
Proof. Lemma 2 tells us that coalition structures $P \in \mathbb{P}$, where $\exists S \in P$ such that $V(S, P)<V\left(S^{\prime}, \bar{P}\right)$, do not belong to $\operatorname{LCS}(G, \ll)$ and $\operatorname{LCS}(G, \ll)$. So, $Y^{1} \subseteq \mathbb{P} \backslash\{P \in$ $\mathbb{P}: \exists S \in P$ for which $\left.V(S, P)<V\left(S^{\prime}, \bar{P}\right)\right\}$. The conditions (P.2) and (P.4) imply that all symmetric coalition structures $P\left(\neq P^{*}\right)$ are such that $V\left(S_{i}, P\right)=V\left(S_{j}, P\right)$ and $V(N)>V\left(S_{i}, P\right)$ for all $S_{i}, S_{j} \in P$ (it implies that $P^{*}>P$ for all $P\left(\neq P^{*}\right)$ symmetric). So, the deviation $P \rightarrow{ }_{N} P^{*}$ (where $P$ symmetric) cannot be deterred since $\nexists P^{\prime}$ such that $P^{\prime} \gg P^{*}$ and $P^{\prime} \in Y^{1}$. Therefore, $\operatorname{LCS}(G, \ll)=\operatorname{LCS}(G, \ll)=\left\{P^{*}\right\}$.

We now show that the stand-alone coalition structure, i.e. the coalition structure consisting only of singletons, is never stable under the largest consistent set based on the indirect weak dominance relation.

Proposition 2 Under (P.1)-(P.4), $\bar{P} \notin L C S(G, \ll)$.

Proof. From Definition 4 and Lemma 2, we have that $Y^{0} \equiv \mathbb{P}$ and $Y^{1}=\left\{P \in \mathbb{P}: \forall P^{\prime}, S\right.$ such that $P \rightarrow_{S} P^{\prime}, \exists P^{\prime \prime} \in Y^{\mathbf{0}}$, where $P^{\prime}=P^{\prime \prime}$ or $P^{\prime} \ll P^{\prime \prime}$, we do not have $V_{i}(\cdot, P) \leq$ $V_{i}\left(\cdot, P^{\prime \prime}\right)$ for all $i \in S$ and $V_{i}(\cdot, P)<V_{i}\left(\cdot, P^{\prime \prime}\right)$ for some $\left.i \in S\right\} \subseteq \mathbb{P} \backslash\{P \in \mathbb{P}: \exists S \in P$ for which $\left.V(S, P)<V\left(S^{\prime}, \bar{P}\right)\right\}$. Next we show that $\bar{P} \notin Y^{2}=\left\{P \in Y^{1}: \forall P^{\prime}, S\right.$ such that $P \rightarrow_{S} P^{\prime}, \exists P^{\prime \prime} \in Y^{1}$, where $P^{\prime}=P^{\prime \prime}$ or $P^{\prime} \ll P^{\prime \prime}$, we do not have $V_{i}(\cdot, P) \leq V_{i}\left(\cdot, P^{\prime \prime}\right)$ for all $i \in S$ and $V_{i}(\cdot, P)<V_{i}\left(\cdot, P^{\prime \prime}\right)$ for some $\left.i \in S\right\}$. Any coalition structure $P \in Y^{1}$ is such that $\forall S \in P: V(S, P) \geq V\left(S^{\prime}, \bar{P}\right)$. By (P.2) and (P.4), the coalition structure $P^{*}=\{N\}$ is efficient and $V(N)>V\left(S^{\prime}, \bar{P}\right)$ for all $i \in N$. Therefore, $\bar{P} \notin Y^{2}$ because the deviation $\bar{P} \rightarrow{ }_{N} P^{*}$ cannot be deterred. Indeed, for all $P^{\prime \prime} \in Y^{1}$, where $P^{*}=P^{\prime \prime}$ or $P^{*} \ll P^{\prime \prime}$, we have $V_{i}(\cdot, \bar{P}) \leq V_{i}\left(\cdot, P^{\prime \prime}\right)$ for all $i \in N$ and $V_{i}(\cdot, \bar{P})<V_{i}\left(\cdot, P^{\prime \prime}\right)$ for some $i \in N$, by (P.1).

However, this results does not hold when we consider the definition of the largest consistent set based on the indirect strict dominance relation. The stand-alone coalition structure, $\bar{P}$, may belong to $\operatorname{LCS}(G, \ll)$.

$$
\begin{array}{ll}
\text { Example 1. } & |N|=4 . \\
\text { Partitions } & \text { Payoffs } \\
\{4\} & (8,8,8,8) \\
\{3,1\} & (4,4,4,12) \\
\{2,2\} & (4,4,4,4) \\
\{2,1,1\} & (3,3,8,8) \\
\{1,1,1,1\} & (4,4,4,4)
\end{array}
$$

Consider Example 1 with four players. Throughout all the examples, we make a slight 
abuse of notation. For instance, $\{3,1\}$ should not be interpreted as a single coalition structure but as the four coalition structures, composed by two coalitions of size 3 and 1, that can be formed by four players. Example 1 shows how the use of the indirect strict or weak dominance matters. Firstly, we characterize $\operatorname{LCS}(G, \ll)$. In the first round of the iterative procedure to compute $\operatorname{LCS}(G, \ll)$, we eliminate the coalition structures $\{2,1,1\},\{2,2\}$ and $\{1,1,1,1\}$. Indeed, the deviations $\{2,1,1\} \rightarrow\{1,1,1,1\},\{2,2\} \rightarrow\{4\}$ and $\{1,1,1,1\} \rightarrow\{4\}$ are not deterred. In the second round, we cannot eliminate other coalition structures since any possible deviations from $\{4\}$ or $\{3,1\}$ are deterred. For instance, the deviation $\{3,1\} \rightarrow\{2,1,1\}$ by one of the player who obtains 4 as payoff is deterred since there exists a sequence of moves $\{2,1,1\} \rightarrow\{1,1,1,1\} \rightarrow\{4\} \rightarrow\{3,1\}$ ending at $\{3,1\}$ such that at each move the deviating players prefer the ending coalition structure to the status-quo they face and the original deviating player is not better off (he obtains still 4 as payoff). Then, $\operatorname{LCS}(G, \ll)=\{\{4\},\{3,1\}\}$. Secondly, we characterize $\operatorname{LCS}(G, \ll)$. We can only eliminate the coalition structure $\{2,1,1\}$. The deviations $\{1,1,1,1\} \rightarrow\{4\}$ and $\{2,2\} \rightarrow\{4\}$ are deterred by the move from $\{4\}$ to $\{3,1\}$. Then, $\operatorname{LCS}(G, \ll)=\{\{4\},\{3,1\},\{2,2\},\{1,1,1,1\}\}$.

\subsection{Cautiously Stable Coalition Structures}

In most economic situations satisfying the conditions (P.1)-(P.4), many coalition structures belong to the largest consistent set. Indeed, the largest consistent set aims to be a weak concept which rules out with confidence. On the contrary, the largest cautious consistent set aims to be better at picking out. The largest cautious consistent set singles out the grand coalition.

Proposition 3 Under $(P .1)-(P .4), \operatorname{LCCS}(G, \ll)=\left\{P^{*}\right\}$ and $\operatorname{LCCS}(G, \ll)=\left\{P^{*}\right\}$.

Proof. From Definition 6 we have $Z^{0}=\mathbb{P}$.

Step one. From Lemma 2 and Definition 6 , it is straightforward that the set of coalition structures $\left\{P \in \mathbb{P}: \exists S \in P\right.$ such that $\left.V(S, P)<V\left(S^{\prime}, \bar{P}\right)\right\}$ does not belong to $Z^{1}$. On the contrary, we can see that $P^{*} \in Z^{1}$. Consider first any possible deviation from $P^{*}$ of any coalition $S$ to any coalition structure $P$ containing only coalitions $S$ with $V(S, P)>V\left(S^{\prime}, \bar{P}\right)$, and such that $P>P^{*}$. By (P.2) and (P.4) the players belonging to the biggest coalition (in size) in any $P \in \mathbb{P} \backslash\left\{P^{*}\right\}$ are worse than in $P^{*}$. From $P$, take the sequence of moves where, at each move, one of the players of the biggest coalition in size deviates to form a singleton, until we arrive to $\bar{P}$. From $\bar{P}$ occurs the deviation to some coalition structure $P^{\prime}$ which is a permutation of players in $P$ (that is, $|P|=\left|P^{\prime}\right|$ and $\forall S \in P$, there exists a coalition $S^{\prime} \in P^{\prime}$ such that $\left.|S|=\left|S^{\prime}\right|\right)$, and such that the 
initial player who has deviated from $P$ is occupying now in $P^{\prime}$ the position of some player $i$ belonging to the coalition $S$ that, initially, has moved from $P^{*}$ to $P$. This means that $P^{\prime} \gg P$ and at least one of the initial deviating players of coalition $S$ from $P^{*}$ (player $i$ ) is worse off in $P^{\prime}$ compared to $P^{*}$. Therefore, every possible deviation from $P^{*}$ to some coalition structure $P$ with all $S \in P$ such that $V(S, P)>V\left(S^{\prime}, \bar{P}\right)$, is deterred because there always exists a coalition structure $P^{\prime}$, with $P^{\prime} \gg P$ and such that $V\left(\cdot, P^{\prime}\right)<V\left(\cdot, P^{*}\right)$ for some player $i \in S$ and $P^{*} \rightarrow_{S} P$. Finally, we have to consider any possible deviation of some coalition $S$ from $P^{*}$ to $P$ with $P>P^{*}$ and such that for some $S^{\prime \prime} \in P$ we have $V\left(S^{\prime \prime}, P\right)<V\left(S^{\prime}, \bar{P}\right)$. If such a deviation does exist, it will be deterred because $\bar{P} \gg P$ and all $i \in N$ get a payoff $V(\cdot, \bar{P})<V\left(\cdot, P^{*}\right)$. Then, $P^{*} \in Z^{1}$, and $Z^{1} \subseteq \mathbb{P} \backslash P \in \mathbb{P}$ : $\exists S \in P$ such that $\left.V(S, P)<V\left(S^{\prime}, \bar{P}\right)\right\}$.

Step two. Take the coalition structure $\bar{P}$ or any other coalition structure $P \in Z^{1} \subseteq$ $\mathbb{P} \backslash\left\{P \in \mathbb{P}: \exists S \in P\right.$ such that $\left.V(S, P)<V\left(S^{\prime}, \bar{P}\right)\right\}$ containing some coalition $S$ that obtains a payoff $V(S, P)=V\left(S^{\prime}, \bar{P}\right)$. Obviously, $\bar{P}$ or $P$ does not belong to $Z^{2}$ since for all $P^{\prime}, S$ such that $P \rightarrow_{S} P^{\prime}$ or $\bar{P} \rightarrow_{S} P^{\prime}$, the expected payoff obtained by assigning positive probabilities to all coalition structures $P^{\prime \prime} \in Z^{1}$, with $P^{\prime}=P^{\prime \prime}$ or $P^{\prime} \ll P^{\prime \prime}$, is strictly preferred to $V(S, P)$ for all players in $S$, given that $P^{*} \gg P^{\prime}$ for all $P^{\prime} \in \mathbb{P}$ and $V(\cdot, \bar{P})<V\left(\cdot, P^{*}\right)$. Using the same reasoning as in step one, one can show that $P^{*} \in Z^{2}$, with $Z^{2} \subseteq \mathbb{P} \backslash\left\{\{\bar{P}\} \cup\left\{P \in \mathbb{P}: \exists S \in P\right.\right.$ such that $\left.\left.V(S, P) \leq V\left(S^{\prime}, \bar{P}\right)\right\}\right\}$.

Step three. Take the coalition structure(s) $P \in Z^{2}$ containing the coalition $S$ that obtains the smallest payoff. Obviously, $P$ does not belong to $Z^{3}$ since for all $P^{\prime}, S$ such that $P \rightarrow_{S} P^{\prime}$, the expected payoff obtained by assigning positive probabilities to all coalition structures $P^{\prime \prime} \in Z^{2}$, with $P^{\prime}=P^{\prime \prime}$ or $P^{\prime} \ll P^{\prime \prime}$, is strictly preferred to $V(S, P)$ for all players in $S$, given that $P^{*} \gg P^{\prime}$ for all $P^{\prime} \in \mathbb{P}$, and $V(S, P)<V\left(\cdot, P^{*}\right)$ for all $i \in S$ (the deviating coalition). One can use the same reasoning used in step one to show that $P^{*} \in Z^{3}$. And so on, until we have eliminated all $P \in \mathbb{P} \backslash\left\{P^{*}\right\}$ (given that, by (P.2) and (P.4), the players belonging to the biggest coalition (in size) in any $P \in \mathbb{P} \backslash\left\{P^{*}\right\}$ are worse than in $\left.P^{*}\right)$.

Now, consider $P^{*}$. From Lemma 3, we know that for all $P \neq P^{*}, P \ll P^{*}$. Then, $\operatorname{LCCS}(G, \ll)=\left\{P^{*}\right\}$ and $\operatorname{LCCS}(G, \ll)=\left\{P^{*}\right\}$, since for all $P^{\prime}, S$ such that $P^{*} \rightarrow{ }_{S} P^{\prime}$, the expected payoff obtained by assigning positive probability to $P^{*}$ (the only coalition structure not yet eliminated in the iterative procedure described above) and with $P^{\prime} \ll P^{*}$, is equally preferred to the payoff obtained in $P^{*}$ for all $i \in S$ (the initial deviating coalition) 
This result is due to the basic idea behind the largest cautious consistent set. Intuitively, at each iteration in the definition of the largest cautious consistent set, we rule out the coalition structure wherein some players receive less or equal than what they could obtain in all candidates to be stable (i.e. all coalition structures not ruled out yet) since these players cannot end worse off by engaging a move.

Example 2. Public goods coalitions with $|N|=4$ and $\alpha=.15$.

Partitions Payoffs

$\{3,1\} \quad(4.08,4.08,4.08,8.13)$

$\{2,2\} \quad(4.87,4.87,4.87,4.87)$

$\{2,1,1\} \quad(3.42,3.42,5.1,5.1)$

$\{1,1,1,1\} \quad(3.5,3.5,3.5,3.5)$

In the first round of the iterative procedure to compute the largest consistent set, we eliminate the coalition structures $\{1,1,1,1\}$ and $\{2,1,1\}$. Indeed, the deviations $\{1,1,1,1\} \rightarrow\{4\}$ and $\{2,1,1\} \rightarrow\{1,1,1,1\}$ are not deterred. In the second round, we cannot eliminate other coalition structures since any possible deviations from $\{4\}$ or $\{3,1\}$ or $\{2,2\}$ are deterred. For example, the deviation $\{3,1\} \rightarrow\{2,1,1\}$ by one of the player who obtains 4.08 as payoff is deterred since there exists a sequence of moves $\{2,1,1\} \rightarrow\{4\} \rightarrow\{3,1\}$ ending at $\{3,1\}$ such that at each move the deviating players prefer the ending coalition structure to the status-quo they face and the original deviating player is not better off (he obtains still 4.08 as payoff). Therefore, the largest consistent set is $\operatorname{LCS}(G, \ll)=\{\{4\},\{3,1\},\{2,2\}\}$.

But $\{3,1\}$ and $\{2,2\}$ do not belong to the largest cautious consistent set. Indeed, the deviation $\{3,1\} \rightarrow\{2,1,1\}$ by one of the player who obtains 4.08 as payoff is not deterred since all coalition structures that indirectly dominate $\{2,1,1\}$ and not yet eliminated are $\{4\},\{3,1\}$ and $\{2,2\}$. Hence, the expected payoff of the original deviating player, obtained by assigning positive probabilities to $\{4\},\{3,1\}$ and $\{2,2\}$, is greater than 4.08 . Once $\{3,1\}$ is eliminated, the deviation $\{2,2\} \rightarrow\{4\}$ is not deterred. Therefore, $\{3,1\}$ and $\{2,2\}$ do not belong to the largest cautious consistent set which singles out $\{4\}$.

\section{Cartel Formation with Quantity Competition}

In the cartel formation game with Cournot competition, the largest consistent set based on the indirect weak dominance relation singles out for $|N| \leq 4$ the grand coalition $P^{*}=\{N\}$. But as $|N|$ grows, many coalition structures may belong to $L C S(G, \ll)$. 


$$
\begin{array}{ll}
\begin{array}{ll}
\text { Example 3. }|N|= \\
\text { Partitions }
\end{array} & \text { Payoffs } \\
\{6\} & (.0417, .0417, .0417, .0417, .0417, .0417) \\
\{5,1\} & (.0222, .0222, .0222, .0222, .0222, .111) \\
\{4,2\} & (.0278, .0278, .0278, .0278, .0556, .0556) \\
\{3,3\} & (.0370, .0370, .0370, .0370, .0370, .0370) \\
\{4,1,1\} & (.0156, .0156, .0156, .0156, .0625, .0625) \\
\{3,2,1\} & (.0208, .0208, .0208, .0312, .0312, .0625) \\
\{2,2,2\} & (.0312 . .0312, .0312, .0312, .0312, .0312) \\
\{3,1,1,1\} & (.0133, .0133, .0133, .0400, .0400, .0400) \\
\{2,2,1,1\} & (.0200, .0200, .0200, .0200, .0400, .0400) \\
\{2,1,1,1,1\} & (.0139, .0139, .0278, .0278, .0278, .0278) \\
\{1,1,1,1,1,1\} & (.0204, .0204, .0204, .0204, .0204, .0204)
\end{array}
$$

In the first round of the iterative procedure to compute the largest consistent set, we eliminate the coalition structures $\{2,1,1,1,1\},\{3,1,1,1\},\{4,1,1\}$. The deviations $\{2,1,1,1,1\} \rightarrow\{1,1,1,1,1,1\},\{3,1,1,1\} \rightarrow\{1,1,1,1,1,1\},\{4,1,1\} \rightarrow\{1,1,1,1,1,1\}$ are not deterred. Also, we can eliminate $\{2,2,1,1\}$ : the deviation $\{2,2,1,1\} \rightarrow\{2,1,1,1,1\}$ is not deterred. In the second round, we delete the coalition structure $\{1,1,1,1,1,1\}$ : the deviation $\{1,1,1,1,1,1\} \rightarrow\{3,3\}$ is not deterred. No more coalition structures can be eliminated at the next rounds. For example, the deviation from $\{2,2,2\}$ to $\{6\}$ is deterred by the further deviation to $\{5,1\}$. Therefore, $\{\{6\},\{5,1\},\{4,2\},\{3,3\},\{3,2,1\},\{2,2,2\}\}$ is the largest consistent set $\operatorname{LCS}(G, \ll)$. The sum of the payoffs associated to coalition structures $\{6\},\{5,1\},\{2,2,2\}$ are $.2502, .222, .1872$, respectively.

We now turn to the characterization of the largest consistent set for $|N| \leq 10$.

Proposition 4 In the cartel formation game under Cournot competition, $L C S(G, \ll)=$ $\left\{P^{*}\right\}$ for $|N| \leq 4$, and $\operatorname{LCS}(G, \ll)=\mathbb{P} \backslash\{\{\bar{P}\} \cup\{P \in \mathbb{P}: \exists S \in P$ such that $V(S, P)<$ $\left.\left.V\left(S^{\prime}, \bar{P}\right)\right\}\right\}$ for $5 \leq|N| \leq 10$.

The proof of this proposition can be found in the appendix. Some remarks can be made. Firstly, $P^{*}$ always belongs to the largest consistent set $\operatorname{LCS}(G, \ll)$ (see Lemma 3 ), while $\bar{P}$ never belongs to $\operatorname{LCS}(G, \ll$ ) (see Proposition 2 ). Secondly, for $10 \geq|N| \geq 5$, all symmetric coalition structures, except $\bar{P}$, belong to $\operatorname{LCS}(G, \ll)$. Finally, all nonsymmetric coalition structures $P$ such that $\nexists S \in P$ with $V(S, P)<V\left(S^{\prime}, \bar{P}\right)$ belong to 
$\operatorname{LCS}(G, \ll)$

We compare now the outcomes obtained under the largest consistent set (and the largest cautious consistent set) with those obtained under a sequential game of coalition formation with fixed payoff division proposed by Bloch (1996). A fixed protocol is assumed and the sequential game proceeds as follows. Player 1 proposes the formation of a coalition $S_{1}$ to which he belongs. Each prospective player answers the proposal in the order fixed by the protocol. If one prospective player rejects the proposal, then he makes a counterproposal to which he belongs. If all prospective players accept, then the coalition $S_{1}$ is formed. All players in $S_{1}$ withdraw from the game, and the game proceeds among the players belonging to $N \backslash S_{1}$. This sequential game has an infinite horizon, but the players do not discount the future. The players who do not reach an agreement in finite time receive a payoff of zero. Contrary to the largest consistent set, this sequential game relies on the commitment assumption. Once some players have agreed to form a coalition they are committed to remain in that coalition.

Consider the following finite procedure to form coalitions. First, player 1 starts the game and chooses an integer $s_{1}$ in the interval $[1,|N|]$. Second, player $s_{1}+1$ chooses an integer $s_{2}$ in $\left[1,|N|-s_{1}\right]$. Third, player $s_{1}+s_{2}+1$ chooses an integer $s_{3}$ in $\left[1,|N|-s_{1}-s_{2}\right]$. The game goes on until the sequence $\left(s_{1}, s_{2}, s_{3}, \ldots\right)$ satisfies $\sum_{j} s_{j}=|N|$. For symmetric valuations, if the finite procedure yields as subgame perfect equilibrium a coalition structure with the property that payoffs are decreasing in the order in which coalitions are formed, then this coalition structure is supported by the (generically) unique symmetric stationary perfect equilibrium (SSPE) of the sequential game (see Bloch, 1996). This result makes easy the characterization of the SSPE outcome of the cartel formation game.

Lemma 4 (Bloch, 1996) In Bloch's sequential coalition formation game under Cournot competition, any symmetric stationary perfect equilibria (SSPE) is characterized by $P=$ $\left\{S^{*},\{i\}_{i \notin S^{*}}\right\}$ where $\left|S^{*}\right|$ is the first integer following $(2 n+3-y) \frac{1}{2}$, where $y=\sqrt{4 n+5}$. If $y$ is an integer, $\left|S^{*}\right|$ can take on the two values $(2 n+3-y) \frac{1}{2}$ and $(2 n+5-y) \frac{1}{2}$.

Intuitively, in the sequential game, firms commit to stay out of the cartel until the number of remaining firms equals the minimal profitable cartel size (this is the smallest coalition size for which a coalition member obtains a higher payoff than if all coalitions are singletons, and is equal to $\left.\left|S^{*}\right|\right)$. From Proposition 4 and Lemma 4 , the relationship between the largest consistent set $\operatorname{LCS}(G, \ll)$ and SSPE follows straightforwardly.

Proposition 5 In the cartel formation game under Cournot competition with $|N| \leq 10$, the coalition structures supported by any symmetric stationary perfect equilibria (SSPE) of Bloch's sequential game always belong to the largest consistent set LCS $(G, \ll)$. 
Assume now that each player belonging to a coalition $S$ have to support a monitoring or congestion cost $c(S)$ which is increasing with the coalition size and has the following functional form. ${ }^{5}$ For all $S \subseteq N, c(S)=c \cdot(|S-1|)^{\phi}$ for $|S|>1$ and $c(S)=0$ for $|S|=1$, with $c, \phi>0$. For $c=0$, the monitoring is said to be costless. For $c>0$, the monitoring is said to be costly. As a result, the per-member expected payoff in a cartel of size $|S|$ becomes for all firms belonging to $S$,

$$
V(S, P)=\frac{(a-d)^{2}}{|S| \cdot(|P|+1)^{2}}-c \cdot(|S-1|)^{\phi} .
$$

It should be noted that, once a monitoring cost is introduced, the valuation still satisfies the properties of positive spillovers, negative association and individual free-riding. However, the grand coalition may be inefficient. Example 4 illustrates that a monitoring cost may refine the largest consistent set and single out the grand coalition.

$$
\begin{array}{ll}
\begin{array}{ll}
\text { Example } 4 .|N|=6, d=0, a=1, c=.00433 \text { and } \phi=.5 . \\
\text { Partitions }
\end{array} & \text { Payoffs } \\
\{6\} & (.0320, .0320, .0320, .0320, .0320, .0320) \\
\{5,1\} & (.0135, .0135, .0135, .0135, .0135, .1110) \\
\{4,2\} & (.0203, .0203, .0203, .0203, .0513, .0513) \\
\{3,3\} & (.0309, .0309, .0309, .0309, .0309, .0309) \\
\{4,1,1\} & (.0081, .0081, .0081, .0081, .0625, .0625) \\
\{3,2,1\} & (.0147, .0147, .0147, .0269, .0269, .0625) \\
\{2,2,2\} & (.0269 . .0269, .0269, .0269, .0269, .0269) \\
\{3,1,1,1\} & (.0072, .0072, .0072, .0400, .0400, .0400) \\
\{2,2,1,1\} & (.0157, .0157, .0157, .0157, .0400, .0400) \\
\{2,1,1,1,1\} & (.0096, .0096, .0278, .0278, .0278, .0278) \\
\{1,1,1,1,1,1\} & (.0204, .0204, .0204, .0204, .0204, .0204)
\end{array}
$$

Applying the iterative procedure to Example 4, we obtain that the largest consistent set $\operatorname{LCS}(G, \ll)$ is $\{\{6\}\}$. The sum of the payoffs associated to coalition structure $\{6\}$ is .192. We observe that the sum of the payoffs is greater than the one associated to some stable coalition structures when monitoring is costless (see Example 3).

In Table 1, we report the coalition structures supported by different solution concepts in the cartel formation game with six firms: SSPE of Bloch's sequential game, $\operatorname{LCS}(G, \ll)$, $\operatorname{LCCS}(G, \ll)$, open membership, game $\Delta$, game $\Gamma$, $\alpha$ stability, $\beta$ stability, and equilibrium

\footnotetext{
${ }^{5}$ Monitoring or congestion costs may emerge because larger coalitions face higher organizational costs, or moral hazard problems as in Espinosa and Macho-Stadler (2002)'s study of cartel formation in a Cournot oligopoly with teams.
} 
binding agreements. ${ }^{6}$ It is shown that, among the concepts or coalition formation games considered, the largest cautious consistent set is the only one to single out the grand coalition. Moreover, this observation holds whatever the number of firms $|N|$, see Table 10.1 in Bloch (1997) and our Proposition 3. ${ }^{7}$

\begin{tabular}{|l|l|}
\hline Concept : & Stable coalition structures : \\
\hline Sequential game (SSPE) & $\{\{5,1\}\}$ \\
\hline$L C S(G, \lll)$ & $\left\{\begin{array}{c}\{5,1\},\{4,2\},\{3,3\}, \\
\{6\},\{3,2,1\},\{2,2,2\}\end{array}\right\}$ \\
\hline LCCS $(G, \ll)$ & $\{\{6\}\}$ \\
\hline Open membership, Game $\Delta$ & $\{\{1,1,1,1,1,1\}\}$ \\
\hline Game $\Gamma, \alpha$ stability, $\beta$ stability & $\{\{6\},\{5,1\}\}$ \\
\hline Equilibrium binding agreements & $\{6\}$ is not an EBA \\
\hline
\end{tabular}

Table 1: Stable coalition structures in the cartel formation game with six firms.

\section{Conclusion}

We have adopted the largest consistent set due to Chwe (1994) to predict which coalition structures are possibly stable in coalition formation games with positive spillovers. We have also introduced a refinement, the largest cautious consistent set. For games satisfying the properties of positive spillovers, negative association, individual free-riding incentives and efficiency of the grand coalition, many coalition structures may belong to the largest consistent set. The grand coalition, which is the efficient coalition structure, always belongs to the largest consistent set and is the unique one to belong to the largest cautious consistent set.

\footnotetext{
${ }^{6}$ See Bloch (1997) for a description of theses concepts or coalition formation games. The open membership game was suggested by $\mathrm{Yi}_{1}(1997)$ and $\mathrm{Yi}$ and Shin (2000). The game $\Delta$ and the game $\Gamma$ are exclusive membership games proposed by Hart and Kurz (1983). The $\alpha$ stability concept and the $\beta$ stability concept are cooperative concepts of stability which have been proposed for games with spillovers by Hart and Kurz (1983). Finally, Ray and Vohra (1997) have proposed a solution concept, the equilibrium binding agreements (EBA), which rules out coalitional deviations which are not themselves immune to further deviations by subcoalitions. Table 10.1 in Bloch (1997) summarizes the outcomes or stable coalition structures in the cartel formation game with $|N|$ firms.

${ }^{7}$ There are no relationships between Ray and Vohra's (1997) EBA concept and $L C S(G, \ll)$ or $\operatorname{LCCS}(G, \ll)$. EBAs exhibit a cyclical pattern, whereby the grand coalition is sometimes a stable coalition structure, sometimes not, depending on $|N|$.
} 


\section{References}

[1] Aumann, R. and J. Drèze, 1974, "Cooperative Games with Coalition Structures," International Journal of Game Theory 3, 217-237.

[2] Bernheim, D., 1984, "Rationalizable Strategic Behavior," Econometrica 52, 10071028.

[3] Bloch, F., 1995, "Endogenous Structures of Association in Oligopolies," RAND Journal of Economics 26 (3), 537-556.

[4] Bloch, F., 1996, "Sequential Formation of Coalitions in Games with Externalities and Fixed Payoff Division," Games and Economic Behavior 14, 90-123.

[5] Bloch, F., 1997, "Non-Cooperative Models of Coalition Formation in Games with Spillovers," in New Directions in the Economic Theory of the Environment (C. Carraro and D. Siniscalco, Eds.), pp.311-352, Cambridge: Cambridge University Press.

[6] Chwe, M.S., 1994, "Farsighted Coalitional Stability," Journal of Economic Theory 63, 299-325.

[7] Espinosa, M.P. and I. Macho-Stadler, 2002, "Endogenous Formation of Competing Partnerships with Moral Hazard," forthcoming in Games and Economic Behavior.

[8] Hart, S. and M. Kurz, 1983, "Endogenous Formation of Coalitions," Econometrica $51,1047-1064$.

[9] Herings, P.J.J. and V.J. Vannetelbosch, 1999, " Refinements of Rationalizability for Normal-Form Games," International Journal of Game Theory 28, 53-68.

[10] Konishi, H., M. Le Breton and S. Weber, 1999, "On Coalition-Proof Nash Equilibria in Common Agency Games," Journal of Economic Theory 85, 122-139.

[11] Pearce, D.G., 1984, "Rationalizable Strategic Behavior and the Problem of Perfection," Econometrica 52, 1029-1050.

[12] Ray, D. and R. Vohra, 1997," Equilibrium Binding Agreements," Journal of Economic Theory 73, 30-78.

[13] Ray, D. and R. Vohra, 1999, "A Theory of Endogenous Coalition Structures," Games and Economic Behavior 26, 286-336.

[14] Ray, D. and R. Vohra, 2001, "Coalitional Power and Public Goods," Journal of Political Economy 109, 1355-1384. 
[15] Yi, S.S., 1997, "Stable Coalition Structures with Externalities," Games and Economic Behavior 20, 201-237.

[16] Yi, S.S. and H. Shin, 2000, "Endogenous Formation of Research Coalitions with Spillovers," International Journal of Industrial Organization 18(2), 229-56.

\section{A Appendix}

\section{Proof of Proposition 4.}

Part 1: $|N| \leq 4$. Simple computations show that each non-symmetric coalition structure $P \in \mathbb{P}$ is such that there exists $S \in P$ with $V(S, P)<V\left(S^{\prime}, \bar{P}\right)$. From Proposition 1, we have $\operatorname{LCS}(G, \ll)=\left\{P^{*}\right\}$ for $|N| \leq 4$.

Part 2: $5 \leq|N| \leq 10$. From Lemmas 2 and 3 and Proposition 2, we have $\{P \in \mathbb{P}: \exists S \in$ $P$ such that $\left.V(S, P)<V\left(S^{\prime}, \bar{P}\right)\right\} \notin L C S(G, \ll), \bar{P} \notin L C S(G, \ll)$ and $P^{*} \in L C S(G, \lll)$, respectively.

To prove that $\left\{P \in \mathbb{P}: P \neq \bar{P}, P^{*}\right.$ and $V(S, P) \geq V\left(S^{\prime}, \bar{P}\right)$ for all $\left.S \in P\right\} \subset$ $\operatorname{LCS}(G, \ll)$, we have to show that all possible deviations from $P$ can be deterred. Two kinds of possible deviations that benefit the deviating players have to be considered.

Firstly, we consider the splitting deviations $P \rightarrow_{S} P^{\prime}$ such that $\left|P^{\prime}\right|>|P|$. The condition (P.1) implies that the players in $N \backslash S$ are worse off in $P^{\prime}$. Then, conditions (P.1) and (P.3) imply that further splitting deviations of players in $N \backslash S$ can occur and lead to some $P^{\prime \prime}$ where $P^{\prime \prime} \rightarrow_{N} P$ and $V\left(\cdot, P^{\prime \prime}\right)<V(\cdot, P)$ for all $i \in N$. Therefore, $P^{\prime} \lll P$ and the deviation $P \rightarrow_{S} P^{\prime}$ is deterred.

Secondly, we consider the enlarging deviations $P \rightarrow_{S} P^{\prime}$ such that $\left|P^{\prime}\right|<|P|$ and $V\left(S, P^{\prime}\right)>V(\cdot, P)$ for all $i \in S$. Then, $P^{\prime}>P$. Notice that by (P.1)-(P.4) and the payoff structure in the cartel formation game (Expression 1) we have $P^{\prime}>P$ if and only if $\left|P^{\prime}\right|<|P|$ and both coalition structures $P$ and $P^{\prime}$ are symmetric. Then, the coalition $S$ which moves from $P$ to $P^{\prime}$ is $S=N$. Two cases should be distinguished:

(i) $P^{\prime}=P^{*}$. Take the deviation $P^{*} \rightarrow_{\{i\}} P^{\prime \prime}$ where player $i$ deviates to form a singleton with $P^{\prime \prime}>P^{\prime}$. It can be shown that $V\left(\cdot, P^{\prime \prime}\right)<V(\cdot, P)$ for some $i \in S=N$ (the initial deviating coalition) and $V\left(\cdot, P^{\prime \prime}\right) \geq V\left(S^{\prime}, \bar{P}\right)$ for all $S^{\prime \prime} \in P^{\prime \prime}$. Then, the deviation $P \rightarrow{ }_{N} P^{*}$ is deterred. From Expression 1 we get, for $S^{\prime \prime} \in P^{\prime \prime}$ such that $\left|S^{\prime \prime}\right|=|N|-1$,

$$
V\left(S^{\prime \prime}, P^{\prime \prime}\right)=\frac{(a-d)^{2}}{9(|N|-1)} \geq \frac{(a-d)^{2}}{(|N|+1)^{2}}=V\left(S^{\prime}, \bar{P}\right) \text { iff }(|N|)^{2}-7(|N|)+10 \geq 0,
$$

condition which is satisfied for $5 \leq|N| \leq 10$. Moreover, we have to show that $V\left(S^{\prime \prime}, P^{\prime \prime}\right)<$ $V(\cdot, P)$ for some $i \in S=N$ (the initial deviating coalition). Since $P$ is symmetric, we have to compare $V\left(S^{\prime \prime}, P^{\prime \prime}\right)$ with the payoff obtained in the symmetric coalition structures. 
Given that $5 \leq|N| \leq 10$ the only symmetric coalition structures we could have are such that their payoffs will be

$$
\frac{(a-d)^{2}}{2\left(\frac{|N|}{2}+1\right)^{2}}, \frac{(a-d)^{2}}{9 \frac{|N|}{2}} \text { for }|N| \text { even, } \frac{(a-d)^{2}}{\frac{|N|}{3}\left(\frac{|N|}{3}+1\right)^{2}} \text { for }|N|=9 .
$$

So,

$$
\begin{aligned}
V\left(S^{\prime \prime}, P^{\prime \prime}\right) & =\frac{(a-d)^{2}}{9(|N|-1)}<\frac{(a-d)^{2}}{2\left(\frac{|N|}{2}+1\right)^{2}} \text { iff } \frac{(|N|)^{2}}{2}-7(|N|)+11<0, \\
V\left(S^{\prime \prime}, P^{\prime \prime}\right) & =\frac{(a-d)^{2}}{9(|N|-1)}<\frac{(a-d)^{2}}{9 \frac{|N|}{2}} \text { iff }|N|>2, \\
V\left(S^{\prime \prime}, P^{\prime \prime}\right) & =\frac{(a-d)^{2}}{9(|N|-1)}<\frac{(a-d)^{2}}{\frac{|N|}{3}\left(\frac{|N|}{3}+1\right)^{2}} \text { iff } \frac{(|N|)^{2}}{9}+\frac{2(|N|)}{3}+1<27-\frac{27}{|N|},
\end{aligned}
$$

and all these conditions are satisfied for $5 \leq|N| \leq 10$. Hence, the deviation $P \rightarrow_{N} P^{*}$ is deterred (with $P$ symmetric).

(ii) $P^{\prime} \neq P^{*}$ (i.e. all players deviate from $P$ to another symmetric coalition structure $P^{\prime}$, with $P^{\prime} \neq P^{*}$ ). From $P^{\prime}$ a player $i$ deviates to form a singleton. That is, $P^{\prime} \rightarrow_{\{i\}} P^{\prime \prime}$. From $P^{\prime \prime}$, take the sequence of moves where, at each move, one of the players belonging to the biggest coalition in size, deviates to form a singleton until we arrive to $\bar{P}$. From $\bar{P}$ occurs the deviation of coalition $N \backslash\{i\}$ to the coalition structure $P^{\prime \prime \prime}$ with $P^{\prime \prime \prime}=\{N \backslash\{i\},\{i\}\}$ and such that $P^{\prime \prime \prime} \gg P^{\prime}$ given that player $i$ (who deviated from $P^{\prime}$ ) is now alone in $P^{\prime \prime \prime}$ and $V\left(\{i\}, P^{\prime \prime \prime}\right)>V\left(\cdot, P^{\prime}\right)$ by (P.1) and (P.2). As before, it is immediate to see that $V\left(\{N \backslash\{i\}\}, P^{\prime \prime \prime}\right)<V(\cdot, P)$ for some player $i \in N$ (the initial deviating coalition) whenever $P$ is symmetric. So, the deviation $P \rightarrow{ }_{N} P^{\prime}$ (with $P$ and $P^{\prime}$ symmetric) is deterred.

Therefore, the enlarging deviations $P \rightarrow_{S} P^{\prime}$ are deterred. 